\title{
Influence of interpenetration on the flexibility of MUV-2
} DOI: $10.1039 / x 0 \times x 00000 x$
Received 00th January 20xx, Accepted 00th January 20xx

\author{
María Vicent-Morales, ${ }^{a}$ Iñigo J. Vitórica-Yrezábal, ${ }^{b}$ Manuel Souto*a and Guillermo Mínguez \\ Espallargas*a
}

The crystal structure of an interpenetrated tetrathiafulvalene(TTF)-based metal-organic framework (MOF) is reported. This MOF, denoted MUV-2-i, is the interpenetrated analogue of the hierarchical and flexible MUV-2. Interestingly, the large flexibility exhibited by MUV-2 upon polar solvent adsorption is considerably reduced in the interpenetrated form which can be explained by short S...S interactions between adjacent TTF-based ligands ensuring more rigidity to the framework. In addition, porosity of MUV-2-i significantly decreased in comparison to MUV-2 as shown by the reduced free volume in the crystal structure.

\section{Introduction}

Metal-organic frameworks (MOFs) or porous coordination polymers (PCPs) are a class of porous crystalline hybrid materials constructed from metal ions or clusters and organic ligands via coordination bonds. Research on MOFs has gathered increased interest because of their structural and functional tunability as well as their high potential applications in gas storage, separation, and catalysis, among others. ${ }^{1-3}$

Flexible or "breathing" MOFs are very interesting materials since they can exhibit large changes in their cell volumes upon external stimuli such as guest inclusion, temperature or pressure. ${ }^{4,5}$ For example, MIL-536, MIL-887, SHF- $61^{8}$ and some soft porous crystals reported by Kitagawa ${ }^{9}$ are materials which can exhibit structural changes upon exposure to external stimuli with defined phase transitions or driven by a continuous breathing process. We have recently reported a highly stable tetrathiafulvalene(TTF)-based MOF, namely MUV-2 (MUV: Materials of University of Valencia), which shows a hierarchical structure with both mesoporous and orthogonal microporous channels. ${ }^{10}$ Moreover, this MOF exhibits a reversible swelling behaviour (up to $40 \%$ of the volume cell) upon polar solvent adsorption which directly impacts on the planarity of the flexible TTF linkers modifying its oxidation potential. ${ }^{11}$ Hence, this material could be very promising to develop new electrochemical sensors.

One limitation of porous materials is interpenetration, also referred as catenation, a common phenomenon observed in MOFs, especially those presenting large pores, where one or

\footnotetext{
a. Instituto de Ciencia Molecular (ICMol), Universidad de Valencia, c/Catedrático José Beltrán, 2, 46980 Paterna, Spain. E-mail: manuel.souto@uv.es, guillermo.minguez@uv.es

b. School of Chemistry, University of Manchester, Oxford Road, Manchester M13 GPL, United Kingdom

Electronic Supplementary Information (ESI) available: CCDC-1897432, genera methods and further characterization of MUV-2-i. See DOI: 10.1039/x0xx00000x
}

more frameworks can grow occupying the void space in order to stabilize the resulting structure which can modify, for example, the morphology, porosity and other functional properties. ${ }^{12,13}$ Although interpenetration is typically considered as an undesired result, it is sometimes accompanied with great benefits, such as improved gas separation capacity. ${ }^{14}$ However, controlling interpenetration to synthesise a crystalline material with a desired porosity and functionalities is still a challenge since it depends on multiple synthetic parameters such temperature, concentration, ${ }^{15}$ modulator, ${ }^{16}$ $\mathrm{pH}^{17,18}$ and ligand design. ${ }^{19,20}$ In addition, partially interpenetrated MOFs can be achieved controlling such parameters with a mixture of interpenetrated and noninterpenetrated components. ${ }^{21,22}$

In a flexible MOF, tuning the breathing behaviour through interpenetration is a very interesting phenomenon in order to modulate and control some of their functional, but this has been scarcely investigated. ${ }^{23}$ For example, Serre and co-workers reported the interpenetrated version of MIL-88, denoted as MIL-126, which shows a rigid structure and permanent porosity in contrast to its non-interpenetrated analogue which exhibits large flexibility. ${ }^{24}$ The rigidity of MIL-126 was attributed to the presence of strong $\pi-\pi$ interactions between adjacent phenyl rings and hydrogen bond contacts which prevented the structure from any shrinkage.

Herein we present the crystal structure of MUV-2$\mathrm{i}$ (pyridine), of formula $(\text { TTFTB })_{3}\left[\left(\mathrm{Fe}_{3} \mathrm{O}\right)(\mathrm{py})_{3}\right]_{2} \cdot 0.36 \mathrm{py}\left(\mathrm{H}_{4}\right.$ TTFTB $=$ tetrathiafulvalene tetrabenzoic acid; py = pyridine), which shows an interpenetrated framework and a remarkable decrease of free volume in comparison to the noninterpenetrated MUV-2. Interestingly, MUV-2-i shows more rigidity when soaking the material with polar solvents such as pyridine or DMF, in contrast to MUV-2, which has been demonstrated to "breathe" upon immersion on these solvents. ${ }^{11}$ 


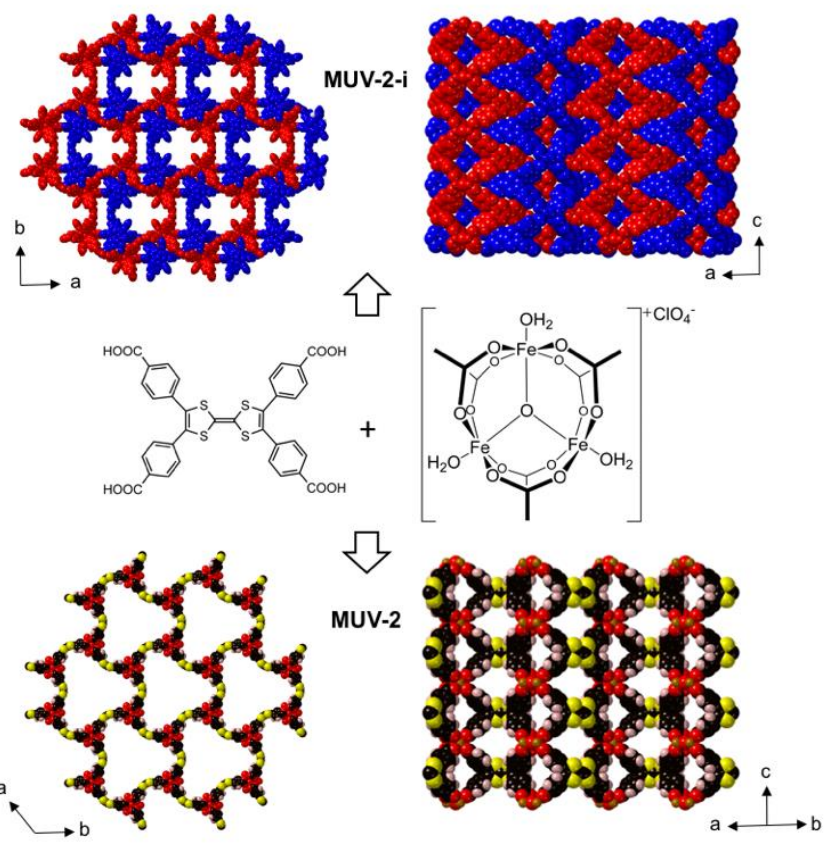

Figure 1. Chemical structures of the ligand and of the $\left[\mathrm{Fe}_{3} \mathrm{O}\left(\mathrm{CH}_{3} \mathrm{COO}\right)_{6}\right] \mathrm{ClO}_{4}$ secondary building unit used in the synthesis of MUV-2-i and MUV-2. Schematic representation of the crystal structures of MUV-2-i (the two interpenetrating nets coloured in red and blue) and MUV-2 along the $c$-axis and perpendicular view of the structure. Black, yellow, red, orange and pink balls represent $\mathrm{C}, \mathrm{S}, \mathrm{O}, \mathrm{Fe}$ and $\mathrm{H}$, respectively.

\section{Results and discussion}

\section{Synthesis of MUV-2-i}

MUV-2-i was synthesised by reacting the preformed cluster $\left[\mathrm{Fe}_{3} \mathrm{O}\left(\mathrm{CH}_{3} \mathrm{COO}\right)_{6}\right] \mathrm{ClO}_{4}{ }^{10}(0.02 \mathrm{mmol})$, tetrathiafulvalene tetrabenzoic acid ( $\mathrm{H}_{4}$ TTFTB) $(0.03 \mathrm{mmol}$ ) with acetic acid ( $1 \mathrm{~mL}$ ) in $4 \mathrm{~mL}$ of $N, N$ dimethylformamide (DMF) at $105^{\circ} \mathrm{C}$ for 48 hours. The crystals were washed with large amount of DMF in order to remove any unreacted starting material, immersed with $\mathrm{EtOH}$ at $65^{\circ} \mathrm{C}$ for $2 \mathrm{~h}$, filtered and dried at $150^{\circ} \mathrm{C}$ in the oven for $2 \mathrm{~h}$, yielding the dried material denoted MUV-2-i(dry). These dark red crystals were soaked in pyridine resulting in MUV-2-i(pyridine), which were used to determine the crystal structure by single-crystal X-ray diffraction. It is important to note that we performed an exhaustive study on the synthetic methodology to control the synthesis of MUV-2-i modifying different parameters (temperature, concentration, solvents, $\mathrm{pH}$ ) obtaining the non-interpenetrated MUV-2 crystal structure most times as checked by powder X-ray diffraction (PXRD) (see Supporting Information). We speculated about the possibility that the ligand used in the synthesis of MUV-2-i contained some traces of $\mathrm{HCl}$ or water as deduced from the NMR spectrum (Figure S1). In order to study the effect of water concentration on the formation of MUV-2-i, we have added small amounts of water to the synthesis reaction (Figure S4) observing in most cases the formation of MUV-2 whereas the presence of a mixture of phases were observed when adding large amount of water. However, we were not able to totally control the reproducibility of the synthesis of MUV-2-i which was obtained only in few cases by serendipity.

\section{Crystal structure of MUV-2-i}

Table 1. Crystal data and structure refinement for MUV-2-i.

\begin{tabular}{|c|c|}
\hline Empirical formula & $\mathrm{C}_{72.79} \mathrm{H}_{45.79} \mathrm{Fe}_{3} \mathrm{~N}_{4.36} \mathrm{O}_{13} \mathrm{~S}_{6}$ \\
\hline Formula weight & 1549.35 \\
\hline Temperature/K & 100.0 \\
\hline Crystal system & orthorhombic \\
\hline Space group & $C 222_{1}$ \\
\hline$a / \AA ̊$ & $34.2069(7)$ \\
\hline$b / \AA ̊$ & $57.0341(9)$ \\
\hline$c / \AA ̊$ & $12.1673(2)$ \\
\hline$\alpha /^{\circ}$ & 90 \\
\hline $8 /{ }^{\circ}$ & 90 \\
\hline $\mathrm{r} /{ }^{\circ}$ & 90 \\
\hline Volume $/ \AA^{3}$ & $23737.9(7)$ \\
\hline Z & 8 \\
\hline$\rho_{\text {calc }} / \mathrm{g} \cdot \mathrm{cm}^{-3}$ & 0.867 \\
\hline$\mu / \mathrm{mm}^{-1}$ & 0.461 \\
\hline$F(000)$ & 6328.0 \\
\hline Crystal size $/ \mathrm{mm}^{3}$ & $0.04 \times 0.02 \times 0.02$ \\
\hline Radiation & $(\lambda=0.6889)$ \\
\hline 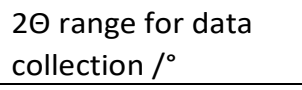 & 3.512 to 49.038 \\
\hline Index ranges & $\begin{array}{l}-41 \leq h \leq 41,-68 \leq k \leq 68,-14 \leq \mathrm{I} \leq \\
14\end{array}$ \\
\hline Reflections collected & 141606 \\
\hline $\begin{array}{l}\text { Independent } \\
\text { reflections }\end{array}$ & $21742\left[R_{\text {int }}=0.1330, R_{\text {sigma }}=0.0744\right]$ \\
\hline $\begin{array}{l}\text { Data / restraints / } \\
\text { parameters }\end{array}$ & 21742 / 2130 / 1114 \\
\hline $\begin{array}{l}\text { Goodness-of-fit on } \\
\text { F }^{2}\end{array}$ & 1.370 \\
\hline $\begin{array}{l}\text { Final } R \text { indexes } \\
{[1>=2 \sigma(I)]}\end{array}$ & $\mathrm{R}_{1}=0.1143, w \mathrm{R}_{2}=0.3166$ \\
\hline $\begin{array}{l}\text { Final } R \text { indexes [all } \\
\text { data] }\end{array}$ & $R_{1}=0.1221, w R_{2}=0.3262$ \\
\hline $\begin{array}{l}\text { Largest diff. } \\
\text { peak/hole / e } \AA^{-3}\end{array}$ & $1.63 /-1.18$ \\
\hline Flack parameter & $0.49(4)$ \\
\hline
\end{tabular}

The crystal structure of MUV-2-i(pyridine) was determined by single-crystal X-ray diffraction measured up to $0.8 \AA$ resolution at the 119 beamline facilities at Diamond Light Source (UK), which is a better resolution than the one observed for the non-interpenetrated MUV-2, in agreement with a better diffraction of a less porous system. MUV-2-i(pyridine) 
crystallises in the orthorhombic system (space group C222 1 ) (Table 1), in contrast to MUV-2 (hexagonal, space group $P-62 m$ ). The unit cell parameters of MUV-2-i(pyridine) are $a=34.2 \AA ; b$ $=57.0 \AA ; c=12.2 \AA\left(V=23737 \AA^{3}\right)$ and, on the basis of the tetratopic TTFTB ligands and six-connected $\mathrm{Fe}_{3} \mathrm{O}(\mathrm{COO})_{6}$ nodes, MUV-2-i can be described as a 3,6-connected network with ttp topology (Figure 1), which is the same than for MUV-2. ${ }^{11}$ Crystal structure of MUV-2-i shows an interwoven network revealing microporous channels of $c a .9 \times 10 \AA$, in contrast to the large hexagonal mesopores of $c a .3 .3 \mathrm{~nm}$ exhibited by MUV-2 in the crystalline phase in which the TTF ligands have a similar degree of bending (MUV-2(31)). ${ }^{11}$

On the other hand, partial view of the MUV-2-i structure along $b$-axis reveals S $\cdots S$ short contacts of 3.45 and $3.6 \AA$ between adjacent TTFTB ligands forming a kind of herringbone stacks (Figure 2) whereas in the non-interpenetrated structure of MUV-2 the S...S distances between adjacent TTFTB ligands along the same axis are considerably larger (9.4 $\AA$ ). Interestingly, the TTFTB molecules in MUV-2-i are significantly distorted with calculated dihedral angles $(\theta)$ formed by the two dithiole rings (planes S1-C1-C2-S2 and S3-C5-C6-S4) of $36^{\circ}$ and $73^{\circ}$, which are much higher than in the case of noninterpenetrated MUV-2 when is also solvated with pyridine $\left(9^{\circ}\right)$. It is important to note that since crystals were immersed in pyridine in both cases, crystal structure shows that three molecules of pyridine are coordinated to $\mathrm{Fe}_{3} \mathrm{O}(\mathrm{COO})_{6}$ nodes instead of water molecules, as it was also observed for MUV2. ${ }^{11}$ Finally, the calculated free space of MUV-2-i is $55 \%$ which is significantly lower than the non-interpenetrated MUV-2 (82 $\%$ ) in agreement with BET calculations from $\mathrm{N}_{2}$ adsorptions (BET values of 410 and $1220 \mathrm{~m}^{2} / \mathrm{g}$, respectively) (Figure 3 ).

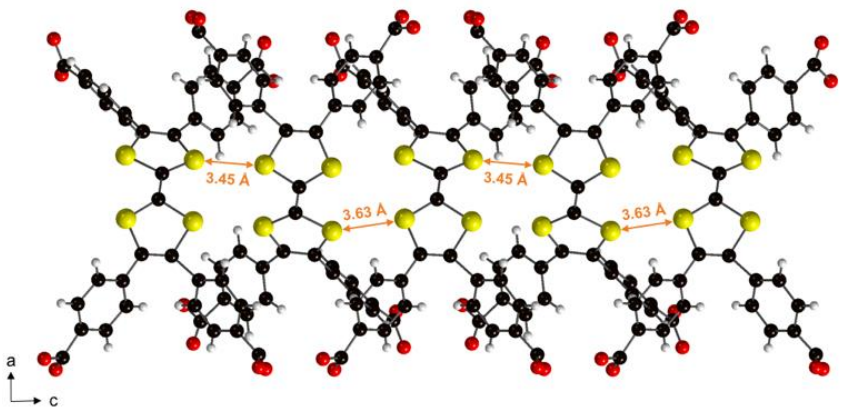

Figure 2. Partial view along $b$-axis of the crystal structure of MUV-2-i showing the distances (3.45 and $3.64 \AA$ A ) of lateral S $\cdots S$ interactions between the TTFTB moieties.

\section{Flexibility of MUV-2-i}

In addition to the expected decrease of free volume caused by interpenetration, we observe a significant quenching of the breathing phenomena characteristic of MUV-2. ${ }^{11}$ Thus, upon immersion to a solvent that opens the structure in MUV-2 (e.g. pyridine or DMF), the powder X-ray diffraction (PXRD) pattern of MUV-2-i reveals that the principal peak is slightly shifted from $2 \theta=3.4^{\circ}(d=25.96 \AA)$ in the desolvated form to $2 \theta=3.1^{\circ}$ ( $d=28.48 \AA$ ) as shown in Figure 4 , in agreement with the simulated pattern from the crystal structure (Figure S3) However, under the same conditions, the principal peak of the non-interpenetrated MUV-2 is shifted to $2 \theta=2.9^{\circ}(d=30.44 \AA$ ) upon soaking the MOF in pyridine or DMF, with a larger pore aperture and a pore diameter of $3.5 \mathrm{~nm}$ (Figure 5). This allows an easy and fast differentiation between the two structures, otherwise difficult to be achieved. Indeed, we were able to identify a mixture of phases in some cases where the appearance of both peaks $\left(2.9^{\circ}\right.$ and $\left.3.1^{\circ}\right)$ indicates the presence of a mixture of MUV-2 and MUV-2-i (Figure S4).

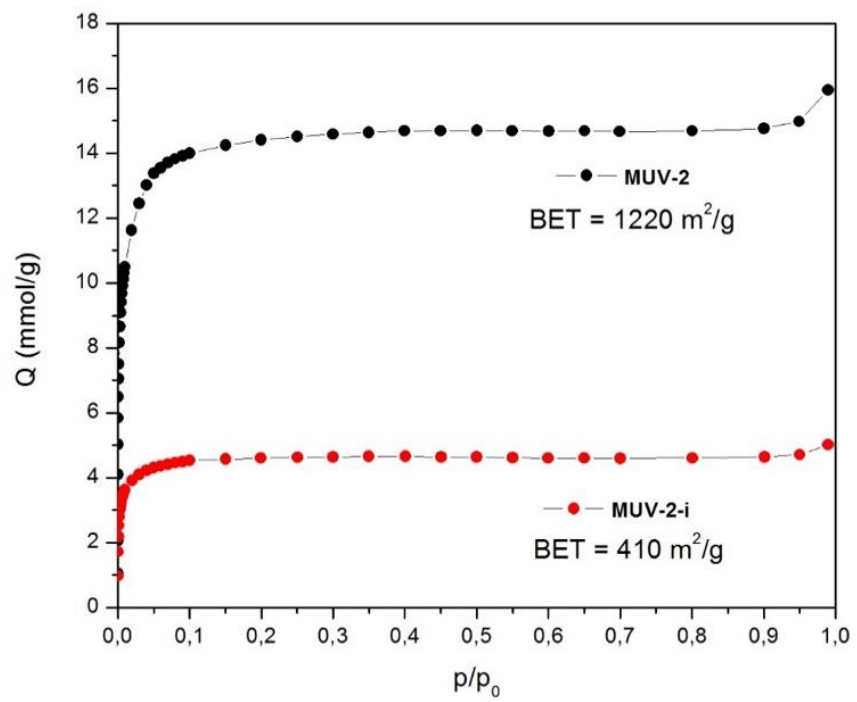

Figure 3. Nitrogen adsorption isotherms at $77 \mathrm{~K}$ on $\mathbf{M U V}-\mathbf{2}$ (black) and MUV-2-i (red).

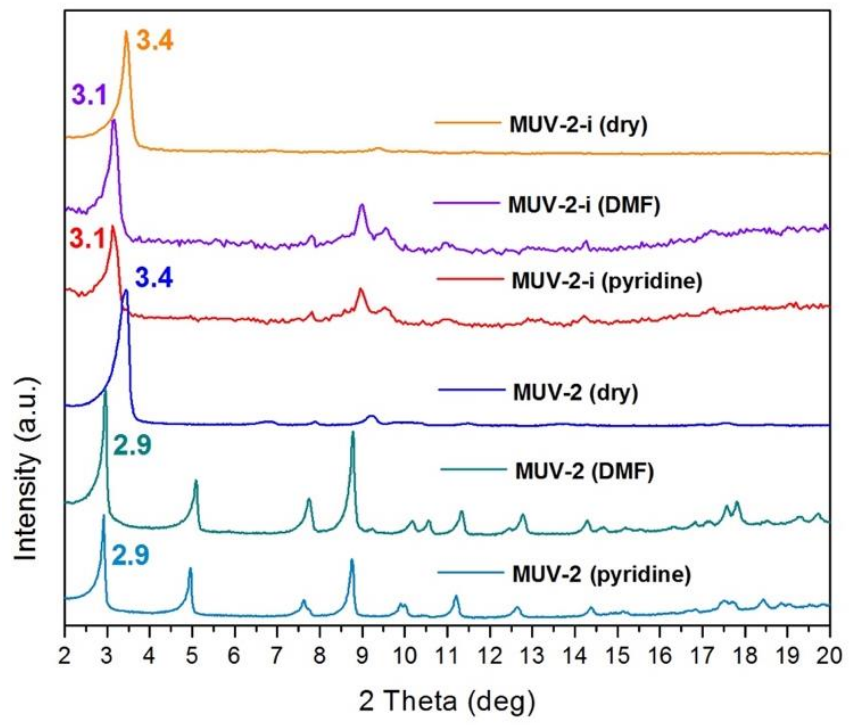

Figure 4. PXRD patterns for MUV-2-i and MUV-2 (dried) and after soaking with pyridine and DMF at room temperature.

Cell parameters were obtained from the PXRD patterns for MUV-2-i and MUV-2 dried, soaked in DMF and soaked in pyridine, in order to compare the different breathing amplitudes (Table 1). The changes in the cell volume between the dried forms and the solvated forms is around $20 \%$ for MUV2-i, which is the half of the breathing amplitude for MUV-2 (ca. 
$40 \%)$ under the same conditions. These values indicate that interpenetrated MUV-2-i presents a smaller breathing behaviour upon solvent adsorption in addition to the reduced nitrogen sorption capacity. These results differ from those for MIL-88 and MIL-126; whereas MIL-88 exhibits a large breathing behaviour upon solvent adsorption (230\% breathing amplitude) but no nitrogen adsorption, MIL-126 shows negligible breathing ( $2 \%$ breathing amplitude) but a larger nitrogen sorption capacity. ${ }^{24}$ In our case, MUV-2-i shows an intermediate degree of flexibility while maintaining the permanent porosity at the same time.

Table 1. Cell parameters and breathing amplitude (\%) of the dried and solvated forms with pyridine and/or DMF for MUV-2, MUV-2-i, MIL-88 and MIL-126. BET surface areas of MUV-2, MUV-2-i, MIL-88 and MIL-126.

\begin{tabular}{|c|c|c|c|c|c|}
\hline & $a(\AA ̊)$ & $c(\AA)$ & $\begin{array}{c}\text { Volume } \\
\qquad\left(\AA^{3}\right)\end{array}$ & $\begin{array}{c}\text { Breathing } \\
\text { amplitude } \\
\qquad \%)^{c}\end{array}$ & $\begin{array}{c}\text { BET } \\
\text { surface } \\
\text { area } \\
\left(\mathrm{m}^{2} / \mathrm{g}\right)^{\mathrm{d}}\end{array}$ \\
\hline $\begin{array}{c}\text { MUV-2 } \\
\text { (dry) }\end{array}$ & 29.5 & 12.5 & 9375 & - & \multirow{3}{*}{1220} \\
\hline $\begin{array}{c}\text { MUV-2 } \\
\text { (pyridine) }\end{array}$ & 35.8 & 12.3 & 13710 & 46 & \\
\hline $\begin{array}{c}\text { MUV-2 } \\
\text { (DMF) }\end{array}$ & 34.9 & 12.4 & 13067 & 39 & \\
\hline $\begin{array}{c}\text { MUV-2-i } \\
(\text { dry })^{a}\end{array}$ & 29.2 & 12.3 & 9051 & - & \multirow{3}{*}{410} \\
\hline $\begin{array}{l}\text { MUV-2-i } \\
\text { (pyridine) }{ }^{a}\end{array}$ & 31.8 & 12.4 & 10846 & 20 & \\
\hline $\begin{array}{l}\text { MUV-2-I } \\
\text { (DMF) a }\end{array}$ & 31.7 & 12.4 & 10760 & 19 & \\
\hline $\begin{array}{l}\text { MIL-88 } \\
\text { (dry) }^{\mathrm{b}}\end{array}$ & 10.2 & 27.6 & 2490 & - & \multirow{2}{*}{ N.A. } \\
\hline $\begin{array}{c}\text { MIL-88D } \\
\text { (pyridine) }\end{array}$ & 20.5 & 22.1 & 8200 & 230 & \\
\hline $\begin{array}{c}\text { MIL-126 } \\
\left(\text { dry) }{ }^{b}\right.\end{array}$ & 21.5 & 35.8 & 16525 & - & \multirow{2}{*}{1750} \\
\hline $\begin{array}{l}\text { MIL-126 } \\
\text { (DMF) }^{\mathrm{b}}\end{array}$ & 21.7 & 35.6 & 16780 & 2 & \\
\hline
\end{tabular}

${ }^{a}$ Refinement performed using the hexagonal cell analogous to MUV2 for ease of comparison. ${ }^{b}$ Values obtained from ref. 24 . ${ }^{\mathrm{c}}$ Amplitude $=\left(V_{\max }-V_{\min } / V_{\min }\right) * 100 \cdot{ }^{d}$ Measured with $\mathrm{N}_{2}$ at $77 \mathrm{~K}$.
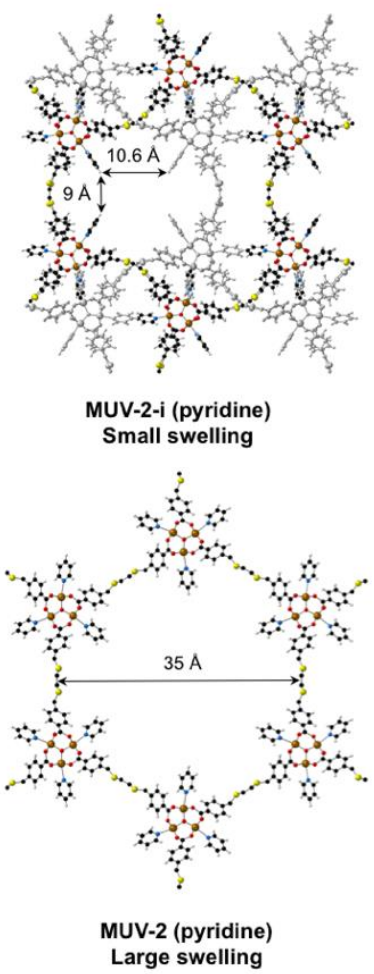

Figure 5. Representation of the pores with distances in the crystal structure of MUV-2-i and MUV-2 when soaking them with pyridine at room temperature. MUV-2-i exhibits a smaller breathing phenomenon than MUV-2.

The weaker breathing behaviour, i.e. smaller pore aperture, which is taking place in the interpenetrated MUV-2-i structure can be explained in terms of intermolecular interactions between the TTFTB moieties. Whereas in the noninterpenetrated structure the TTFTB ligands are considerably far with $\mathrm{S} \cdots \mathrm{S}$ distances of $9.4 \AA$ A between adjacent ligands along the $b$-axis, the interpenetrated MUV-2-i structure reveals S...S short contacts of $3.45 \AA$ (Figure 2) which could be responsible for the largest rigidity of the framework.

\section{Conclusions}

In summary, we have reported the interpenetrated structure MUV-2-i, an analogue MOF of the flexible and hierarchical MUV-2, albeit exhibiting reduced free volume and decreased pore sizes. In addition, the structure becomes more rigid than the non-interpenetrated MUV-2 structure when the MOF is solvated with polar solvents probably due to short S...S interactions between the TTFTB ligands. We believe that this study will be useful for the scientific community to distinguish between interpenetrated/non-interpenetrated structures and to further understand how to fully control the synthesis and properties of each structure. 


\section{Conflicts of interest}

There are no conflicts to declare.

\section{Acknowledgements}

The work has been supported by the European Union (ERC2016-CoG 724681-S-CAGE) and the Spanish MICINN (CTQ201789528-P). We also thank the Spanish government for the provision of a Maria de Maeztu project (MDM-2015-0538). G.M.E. and M.S. thank MICINN for a Ramón y Cajal and a Juan de la Cierva-Formación fellowships, respectively. We thank the Diamond Light Source (UK) for the synchrotron beamtime.

\section{Notes and references} H. Furukawa, K. E. Cordova, M. O'Keeffe and O. M. Yaghi, Science, 2013, 341, 1230444.

2 H.-C. Zhou and S. Kitagawa, Chem. Soc. Rev., 2014, 43, 5415-5418.

3 G. Maurin, C. Serre, A. Cooper and G. Férey, Chem. Soc. Rev., 2017, 46, 3104-3107. A. Schneemann, V. Bon, I. Schwedler, I. Senkovska, S. Kaskel and R. A. Fischer, Chem. Soc. Rev., 2014, 43, 60626096. R. E. Morris and L. Brammer, Chem. Soc. Rev., 2017, 46 5444-5462. C. Serre, F. Millange, C. Thouvenot, M. Noguès, G. Marsolier, D. Louër and G. Férey, J. Am. Chem. Soc., 2002, 124, 13519-13526. G. Férey, C. Mellot-Draznieks, C. Serre, F. Millange, J. Dutour, S. Surblé and I. Margiolaki, Science, 2005, 309, 2040-2042. E. J. Carrington, C. A. McAnally, A. J. Fletcher, S. P. Thompson, M. Warren and L. Brammer, Nat. Chem., 2017, 9, 882-889. H. Sato, W. Kosaka, R. Matsuda, A. Hori, Y. Hijikata, R. V Belosludov, S. Sakaki, M. Takata and S. Kitagawa, Science, 2014, 343, 167-170. M. Souto, A. Santiago-Portillo, M. Palomino, I. VitoricaYrzebal, B. J. C. Vieira, J. C. C. Waerenborgh, S. Valencia, S. Navalon, F. Rey, H. Garcia and G. Minguez Espallargas, Chem. Sci., 2018, 9, 2413-2418. M. Souto, J. Romero, J. Calbo, I. J. Vitorica-Yrezabal, J. L. Zafra, J. Casado Cordón, E. Ortí, A. Walsh and G. Minguez Espallargas, J. Am. Chem. Soc., 2018, 140, 10562-10569. H. L. Jiang, T. A. Makal and H. C. Zhou, Coord. Chem. Rev., 2013, 257, 2232-2249.

13 Y. N. Gong, D. C. Zhong and T. B. Lu, CrystEngComm, 2016, 18, 2596-2606.

14 P. Nugent, Y. Belmabkhout, S. D. Burd, A. J. Carins, R. Luebke, K. Forrest, T. Pham, S. Ma, B. Space, L. Wojtas, M. Eddaoudi and M. J. Zaworotko, Nature, 2013, 495, 80-84. J. J. Zhang, L. Wojtas, R. W. Larsen, M. Eddaoudi and M. J. Zaworotko, J. Am. Chem. Soc., 2009, 131, 17040-17041.
2011, 2556-2558.

K. P. Rao, M. Higuchi, J. Duan and S. Kitagawa, Cryst. Growth Des., 2013, 13, 981-985. S. Surinwong, N. Yoshinari, T. Kojima and T. Konno, Chem. Commun., 2016, 52, 12893-12896.

O. K. Farha, C. D. Malliakas, M. G. Kanatzidis and J. T. Hupp, J. Am. Chem. Soc., 2010, 132, 950-952. R. J. Marshall, C. T. Lennon, A. Tao, H. M. Senn, C. Wilson, D. Fairen-Jimenez and R. S. Forgan, J. Mater. Chem. A, 2018, 6, 1181-1187. S. Yang, X. Lin, W. Lewis, M. Suyetin, E. Bichoutskaia, J. E. Parker, C. C. Tang, D. R. Allan, P. J. Rizkallah, P. Hubberstey, N. R. Champness, K. M. Thomas, A. J. Blake and M. Schröder, Nat. Mater., 2012, 11, 1-7.

D. O. Nolan, D. G. Madden, A. Kumar, K. Chen, T. Pham, K. A. Forrest, E. Patyk-kazmierczak, Q. Yang, C. A. Murray, C. C. Tang and M. J. Zaworotko, Chem. Commun., 2018, 54, 3488-3491. J. H. Park, W. R. Lee, Y. Kim, H. J. Lee, D. W. Ryu and W. J. Phang, Cryst. Growth Des., 2014, 14, 699-704. M. Dan-Hardi, H. Chevreau, T. Devic, P. Horcajada, G. Maurin, G. Férey, D. Popov, C. Riekel, S. Wuttke, J. C. Lavalley, A. Vimont, T. Boudewijns, D. De Vos and C. Serre, Chem. Mater., 2012, 24, 2486-2492. 